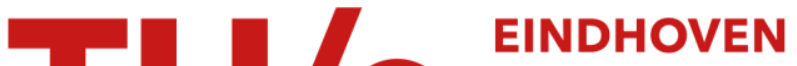

\section{Mechanism and dynamics of the CO-induced lifting of the $\mathrm{Pt}(100)$ surface reconstruction}

\section{Citation for published version (APA):}

Beurden, van, P., Bunnik, B. S., Kramer, G. J., \& Borg, A. (2003). Mechanism and dynamics of the CO-induced lifting of the Pt(100) surface reconstruction. Physical Review Letters, 90(6), 066106-1/4. [066106].

https://doi.org/10.1103/PhysRevLett.90.066106

DOI:

10.1103/PhysRevLett.90.066106

Document status and date:

Published: 01/01/2003

\section{Document Version:}

Publisher's PDF, also known as Version of Record (includes final page, issue and volume numbers)

\section{Please check the document version of this publication:}

- A submitted manuscript is the version of the article upon submission and before peer-review. There can be important differences between the submitted version and the official published version of record. People interested in the research are advised to contact the author for the final version of the publication, or visit the $\mathrm{DOI}$ to the publisher's website.

- The final author version and the galley proof are versions of the publication after peer review.

- The final published version features the final layout of the paper including the volume, issue and page numbers.

Link to publication

\section{General rights}

Copyright and moral rights for the publications made accessible in the public portal are retained by the authors and/or other copyright owners and it is a condition of accessing publications that users recognise and abide by the legal requirements associated with these rights.

- Users may download and print one copy of any publication from the public portal for the purpose of private study or research.

- You may not further distribute the material or use it for any profit-making activity or commercial gain

- You may freely distribute the URL identifying the publication in the public portal.

If the publication is distributed under the terms of Article 25fa of the Dutch Copyright Act, indicated by the "Taverne" license above, please follow below link for the End User Agreement:

www.tue.nl/taverne

Take down policy

If you believe that this document breaches copyright please contact us at:

openaccess@tue.nl

providing details and we will investigate your claim. 


\title{
Mechanism and Dynamics of the CO-Induced Lifting of the Pt(100) Surface Reconstruction
}

\author{
P. van Beurden, ${ }^{*}$ B. S. Bunnik, and G. J. Kramer ${ }^{\dagger}$ \\ Schuit Institute of Catalysis, Eindhoven University of Technology, P.O. Box 513, 5600 MB Eindhoven, The Netherlands
}

A. Borg

Department of Physics, Norwegian University of Science and Technology, N-7491 Trondheim, Norway

(Received 13 September 2002; published 14 February 2003)

\begin{abstract}
The first atomistic simulations of the CO-induced lifting of the $\mathrm{Pt}(100)$-hex reconstruction have been performed. During this phase transformation the surface changes back to bulk-terminated $\mathrm{Pt}(100)-(1 \times$ 1 ), whereby the surface atom density decreases by $\sim 20 \%$. The simulations reveal a mechanism collective in nature, indicating that restructuring proceeds through ejection of chains of $\mathrm{Pt}$ atoms. These chains explain the anisotropy as seen in scanning tunneling microscopy experiments. The restructuring rate depends nonlinearly on the $\mathrm{CO}$ coverage, but the absence of local clustering of $\mathrm{CO}$ excludes an explanation in terms of elementary reaction kinetics as proposed previously.
\end{abstract}

DOI: 10.1103/PhysRevLett.90.066106

One of the most intensively studied systems in surface science is adsorption of $\mathrm{CO}$ on $\mathrm{Pt}(100)$, for reasons of fundamental as well as applied interest. The oxidation of $\mathrm{CO}$ on $\mathrm{Pt}(100)$ has a similar archetypal role in catalysis. Among its most interesting features is the oscillatory behavior of the reaction under certain conditions [1,2]. The reason for this behavior is related to the different reactivity of the two surface phases that $\mathrm{Pt}(100)$ exhibits, towards the reactants. The clean $\operatorname{Pt}(100)$ surface is reconstructed, exposing a quasihexagonal close-packed top layer (Fig. 1). This reconstruction, normally referred to as the hex phase, which undergoes a slight rotation of $0.7^{\circ}$ above about $1100 \mathrm{~K}$, restructures to the regular, bulkterminated square $(1 \times 1)$ phase upon adsorption of $\mathrm{CO}$, $\mathrm{NO}$, and several other adsorbates. The hex surface plane contains $20 \%$ to $25 \%$ more $\mathrm{Pt}$ atoms than the square surface plane, and it is generally believed that these excess surface atoms are forced up during the surface deconstruction, to become adatoms, which can coalesce to form islands and steps. Our current understanding of the mechanism of this CO-induced hex $\rightarrow(1 \times 1)$ phase transition is based on experimental data obtained by several research groups, using techniques including LEED, infrared spectroscopy, molecular beam, and scanning tunneling microscopy (STM). In this Letter, we show that a theoretical study can reproduce some of the finer details of these experiments and at the same time contribute to a deeper understanding of the atomistic driving forces of the process. The method we employ is a novel approach to adsorbate/surface systems, using a density functional theory (DFT) based parametrization of modified embedded-atom method potentials, enabling for the first time molecular dynamics (MD) simulations of the adsorbate-induced lifting of a surface reconstruction. These MD simulations reveal for CO/Pt(100)-hex a restructuring mechanism which is collective in nature.

The experimental studies mentioned above revealed that even at $\mathrm{CO}$ coverages below 0.1 monolayers (ML)
PACS numbers: 68.35.Bs, 64.60.-i, 82.20.Wt

the phase transition occurs locally at temperatures around 300 to $500 \mathrm{~K}$ [4-6]. However, where it occurs, the local $\mathrm{CO}$ coverage on the resulting $(1 \times 1)$ patches is $0.5 \mathrm{ML}$ $[4,7]$. When the overall CO coverage on a fully restructured surface drops below $\sim 0.3 \mathrm{ML}$, the hex phase starts to reappear $[4,8]$. Further, it was concluded that the restructuring is heterogeneously nucleated at linear defects. Subsequent growth of the arisen $(1 \times 1)$ domains proceeds anisotropically, the preferred direction being [011] (Ref. [9]), with a rate that depends in a highly nonlinear fashion on the local CO coverage [10].

On the theoretical side, when tackling this system one faces the problem of the large number of atoms involved, which makes DFT impossible at the present. A further complication is the fact that current DFT implementations are not able to reproduce the correct binding sites of

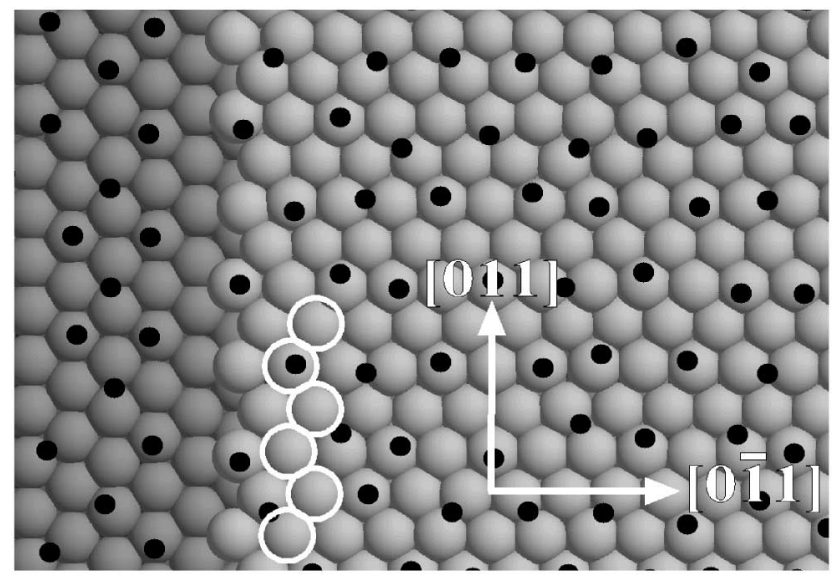

FIG. 1. Top view of $\mathrm{Pt}(100)$-hex with CO adsorbed (represented by the smaller black dots). Darker colors correspond to lower levels. The $(5 \times 1)$ unit cell, indicated by the white circles where six atoms are on top of five substrate atoms in the [011] direction, is used in our simulations to model the real $(5 \times 29)$ quasihexagonal periodic unit cells (Ref. [3]). 
$\mathrm{CO}$ on Pt [11]. Theoretical modeling using lattice-gas methods, such as Monte Carlo simulations, has been successfully applied to study the oscillatory behavior of $\mathrm{CO}$ on $\mathrm{Pt}(100)$ [12-16] as well as the CO-induced lifting of the $\mathrm{Pt}(110)-(2 \times 1)$ missing row reconstruction [17]. Lattice-gas simulations, however, are possible only when the system undergoes rearrangement of atoms on a fixed, predefined lattice. It is precisely the absence of such a fixed lattice in the hex $\rightarrow(1 \times 1)$ phase transition which makes it impossible to study the restructuring process on $\operatorname{Pt}(100)$ with lattice-gas methods.

Recently, we have shown that molecular simulations using the modified embedded-atom method (MEAM) [18], are able to describe a wide range of surface properties of transition metals $[19,20]$. It is this method that, in terms of number of particles and time scale, allows in principle investigation of systems at the required scale, such as the adsorbate-induced lifting of a surface reconstruction. We have developed a potential parametrization for the $\mathrm{CO} / \mathrm{Pt}$ system, based on DFT calculations as well as experimental data, that correctly takes into account the $\mathrm{CO}-\mathrm{CO}$ lateral interaction and adsorption energies of $\mathrm{CO}$ at different surface sites on the (100) and (111) surfaces [20]. The adsorption energy of CO on the (100)-hex surface phase was, however, not included in the parameter fit data. The difference in adsorption energy on the $(1 \times 1)$ and hex phases of $\operatorname{Pt}(100)$ - with our current MEAM parametrization $0.2 \mathrm{eV} /$ atom - is believed to be the driving force of the surface restructuring and is therefore crucial in correct modeling of this system. It is worth noting that here we treat the $\mathrm{CO}$ molecule as an effective atom. This can be justified when one realizes that $\mathrm{CO}$ binds only to the $\mathrm{Pt}$ surface through the $\mathrm{C}$ atom. Further, in vacuum, the hex phase is predicted by our MEAM potential to be favored over the $(1 \times 1)$ phase by $0.1 \mathrm{eV} /$ atom, which agrees reasonably well with the experimental value of $0.2 \mathrm{eV} /$ atom [21].

In our MD simulations, with time steps of $1 \mathrm{fs}$, we applied higher values for the temperature and the local CO coverage than was used experimentally, in order to accelerate the restructuring process: the $\mathrm{CO}$ coverage $\theta$ was varied between 0.4 and $0.5 \mathrm{ML}$. After equilibrating at $100 \mathrm{~K}$, the simulation temperatures were raised to values between 750 and $950 \mathrm{~K}$. In all cases, similar behavior was observed. The simulations were performed using periodic seven-layered slabs with two perpendicular oriented hex domains, of which one is elevated one layer to mimic a step, see Fig. 1, making a total of 1800 surface atoms. No constraints have been imposed on the atoms in each slab, except for the bottom layer, which has been kept fixed. The hex reconstruction is modeled by $(5 \times 1)$ unit cells on top of a $(1 \times 1)$ substrate. These $(5 \times 1)$ unit cells are for our purposes equivalent to the larger $(5 \times 29)$ unit cells-i.e., with respect to the restructuring mechanism and surface energies - but allow for smaller simulation slabs, and hence longer simulation times (up to $1 \mathrm{~ns}$ ) and better statistics.
Our simulations reveal a restructuring mechanism that is collective in nature, in the sense that entire chains of $\mathrm{Pt}$ atoms are squeezed out of the hex surface and forced up to become adatoms, allowing the remaining surface atoms to rearrange and adopt the bulk-terminated square symmetry. These chains constitute the $\sim 20 \%$ excess atoms; see Fig. 2.

A closer inspection reveals that the rows of surface atoms that are ejected are typically the ones which are, due to the misfit between atoms in the hex and square planes, closest to an on-top position with respect to the second layer atoms. Each two rows adjacent to these ontop surface rows close in through a zipperlike action to become neighboring rows and thereby sequentially forcing up the on-top atoms. From Fig. 2, the ejection occurs on the order of a few atoms per ps. In contrast, inspection of the trajectory of every $\mathrm{CO}$ molecule indicates that $\mathrm{CO}$ jumps 4 to 6 times on average, during the entire simulation time of $0.5 \mathrm{~ns}$. In agreement with STM observations
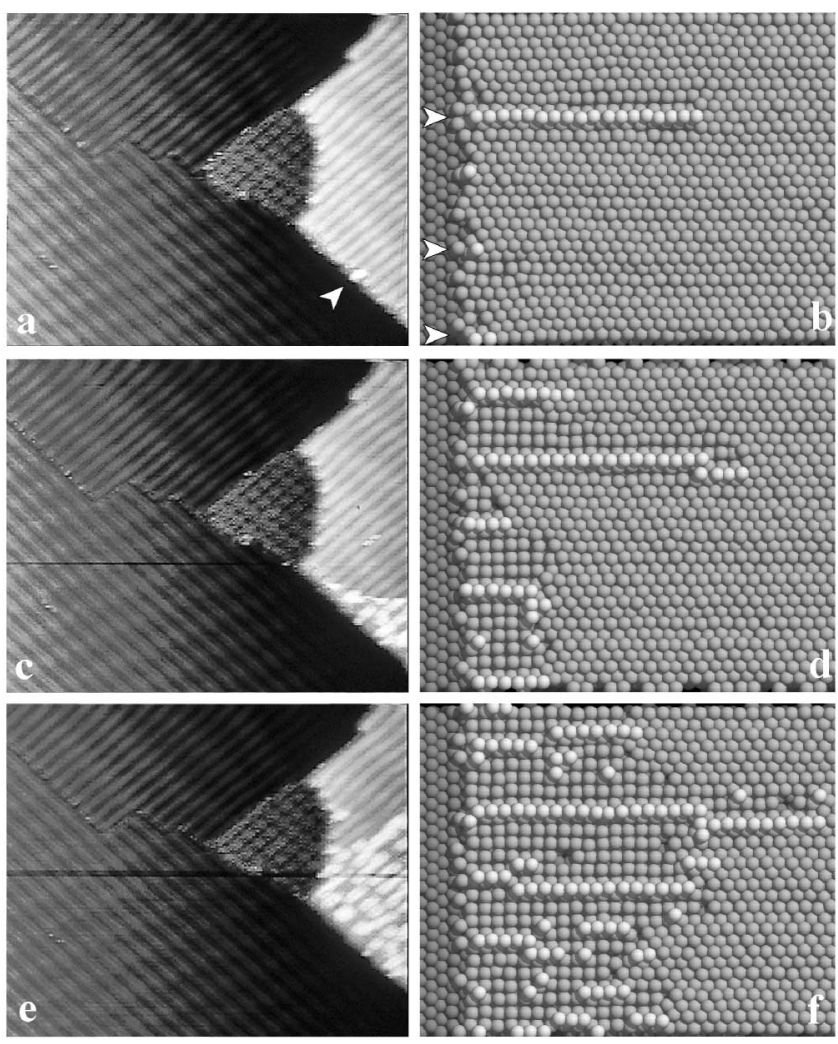

FIG. 2. Successive STM and MD/MEAM simulation snapshots of the initial CO-induced lifting of the $\mathrm{Pt}(100)$-hex reconstruction. The CO exposure in the STM images (a), (c), and (e) ranges from 0.2 to $1.2 \mathrm{~L}, 1 \mathrm{~L}=10^{-6}$ Torr $\cdot \mathrm{s}$ (for further experimental details, see Ref. [9]). In the simulation images (b), (d), and (f), the CO coverage is $0.5 \mathrm{ML}$. For clarity $\mathrm{CO}$ is not shown. The simulation snapshots cover a simulation time of $\sim 0.5 \mathrm{~ns}$. The simulation results clearly indicate that the observed anisotropy in the STM measurements is caused by chains of surface atoms being collectively ejected, nucleated at the step (marked by the arrows). 
[9], the phase transition is found to be heterogeneously nucleated. The nucleation centers are linear defects such as steps, causing disruption of the hexagonal structure in the [011]-trough direction (i.e., the step edge is aligned along the [011] direction). We should note, however, that homogeneous nucleation was also found to be possible in our simulations on a planar, nonstepped surface, but requires a higher activation energy and proceeds at a much lower rate (for an accurate investigation even beyond our current computational possibilities).

The phenomenon of ejected chains and their nucleation only at "perpendicular" [011] steps is easily explained when one considers the activation of such a process: ejecting a single $\mathrm{Pt}$ atom would involve more $\mathrm{Pt}$-Pt bonds to be broken and is therefore energetically less favorable. Furthermore, perpendicular steps enhance the ejection, since one end of the chain to be ejected is already disconnected from the hex surface. In addition to that, the step energy of these more open, perpendicular steps is higher than the step energy of the more closed steps parallel to [011] (approximately $0.1 \mathrm{eV} / \AA$ according to our MEAM potential), which means that the steps parallel to [011] are less favorable and thus more prone to rearrangement. This also explains why Ritter and coworkers [22] in their STM measurements on a part of the surface with only "inert" steps along [011] did not see nucleation at these steps.

The activation energy $E_{a}$ of the restructuring process can be determined using Arrhenius's law. The $(1 \times 1)$ growth rate $r$ is related to temperature $T$ by

$$
r=r_{0} \exp \left(-E_{a} / k_{B} T\right) \text {. }
$$

$E_{a}$ is found to be $0.45 \pm 0.1 \mathrm{eV}$ at $\theta=0.5 \mathrm{ML}$ (Fig. 3). This rather modest value for $E_{a}$ agrees with the experimental observation of restructuring occurring at temperatures as low as $150 \mathrm{~K}$ [23]. This is to be compared with the $(1 \times 1) \rightarrow$ hex transition on clean $\operatorname{Pt}(100)$, which has an activation energy of about $1 \mathrm{eV}$ and occurs only around $400 \mathrm{~K}$ [24]. When varying the CO coverage $\theta$ on the initial hex surface, the growth rate $r$ is found to vary nonlinearly with $\theta$, but due to the large statistical error in our results, the order $\nu$ of the reaction cannot be specified better than $\nu=7.5 \pm 2.5$, Fig. 4 . The nonlinear dependence is in line with experiment, where the relation $r \propto$ $\theta^{\nu}, \nu=4.5 \pm 0.4$ was found [10]. It is interesting to realize that at the higher coverages employed in our simulations, we do not find evidence for a simple kinetic model as suggested by Hopkinson et al. [10] and Ali et al. [25], where four to five $\mathrm{CO}$ molecules approach and somehow locally convert a few $\mathrm{Pt}$ atoms with hexagonal symmetry, to become square. In our simulations, no local clustering of four to five (or, from our value of $\nu$, five to ten) $\mathrm{CO}$ molecules is observed at the nucleation centers of the phase transformation (Fig. 5). This suggests highly complex kinetics are involved and, in contrast to the empirical model described above, the mechanism observed here is not diffusion limited in the sense that a

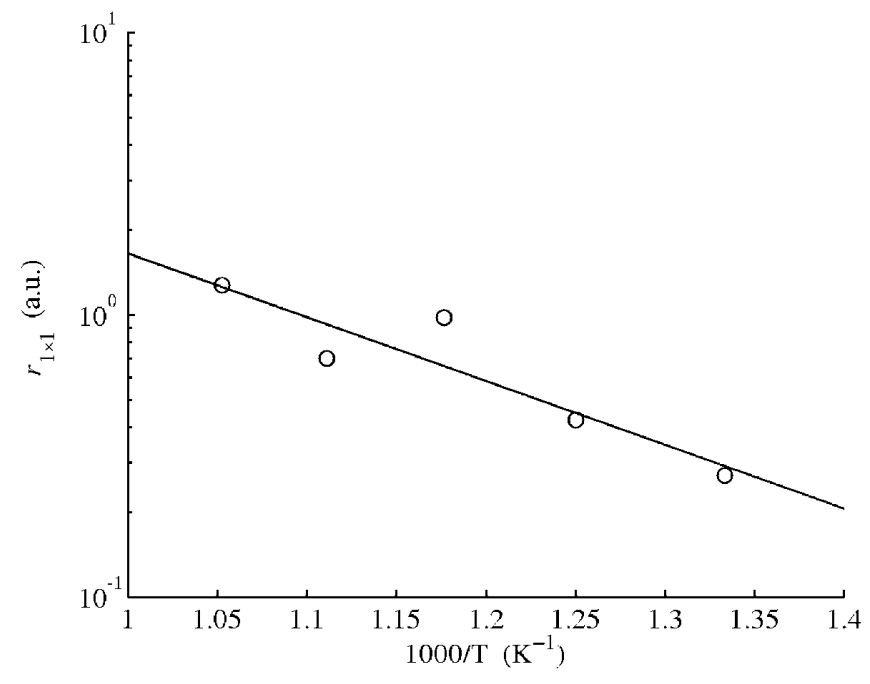

FIG. 3. Arrhenius plot of the rate of the restructuring process at $\theta=0.5 \mathrm{ML}$. The activation energy $E_{a}$ is found to be $0.45 \pm 0.1 \mathrm{eV}$.

certain number of $\mathrm{CO}$ molecules should cluster in order to initiate restructuring. It appears from our simulation results that the adsorbed $\mathrm{CO}$ molecules initiate surface relaxations and a shear tension between adjacent [0 $\overline{1} 1]$ rows, due to the preference for a square over a hexagonal coordination sphere. This creates an environment in which $\mathrm{Pt}$ atoms can be sequentially squeezed out of the surface to form chains of adatoms, and realignment of the remaining surface area becomes possible. With this cooperative ejection and rearrangement of $\mathrm{Pt}$ atoms, the entire concentration of $\mathrm{CO}$ molecules in the vicinity to the critical area is involved, since, in general, surface relaxations and tension are not restricted to a few atoms only, but extend over several atomic distances.

The results addressed above are in line with the Monte Carlo simulations by Kuzovkov et al. [26], who managed

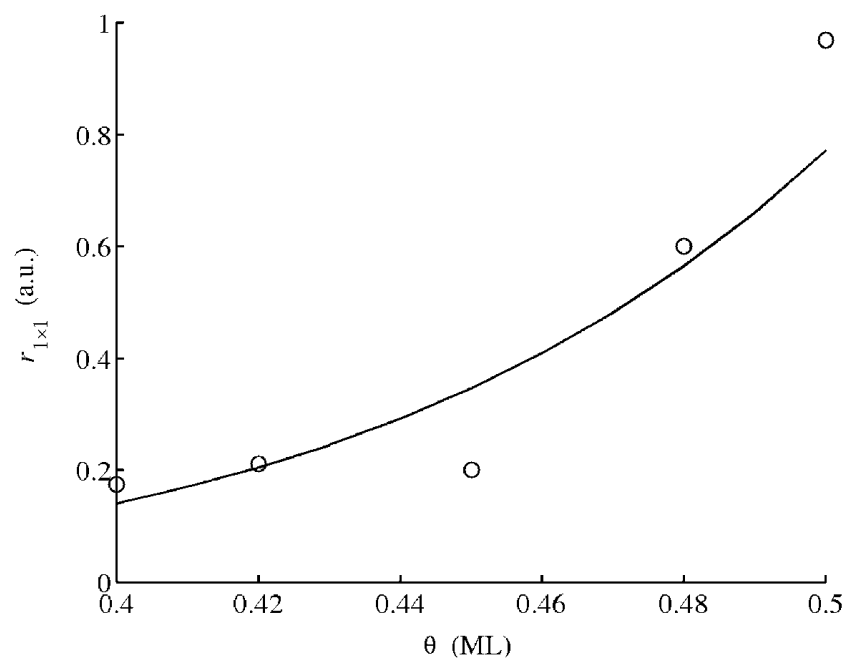

FIG. 4. Restructuring rate $r$ as a function of CO coverage. The drawn line represents the nonlinear relationship: $r \propto$ $\theta^{7.5 \pm 2.5}$. 


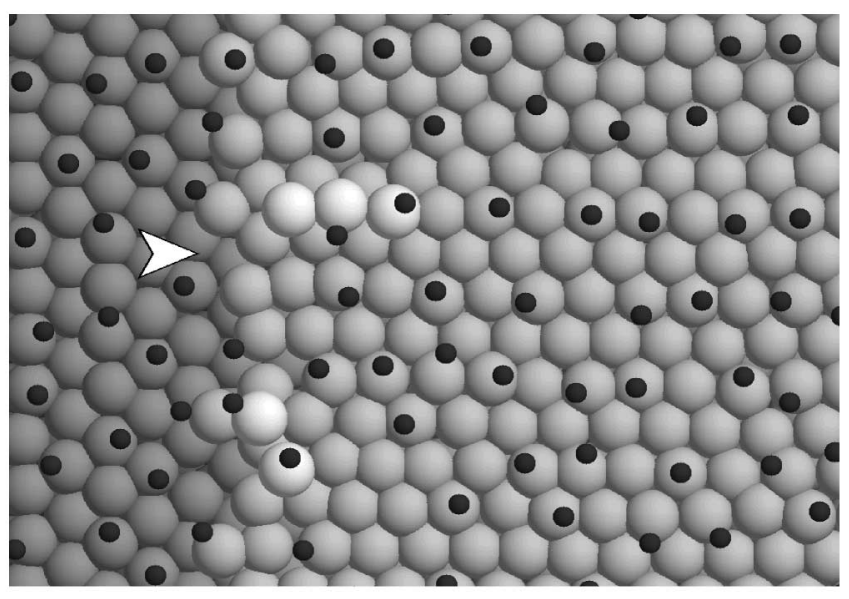

FIG. 5. Snapshot of the initial stage of the restructuring of $\operatorname{Pt}(100)$-hex $(\theta=0.4 \mathrm{ML})$. The smaller black dots represent $\mathrm{CO}$. As seen there is no significant clustering of $\mathrm{CO}$ molecules around the nucleation center at the step, marked by the arrow.

to reproduce the nonlinear coverage dependence of the growth rate as well, using a model in which the phase transition is nucleated by cooperative processes, without any local clustering of $\mathrm{CO}$.

In conclusion, the first atomistic simulations of the COinduced lifting of the $\mathrm{Pt}(100)$-hex reconstruction have been performed and the results indicate that the restructuring proceeds through cooperative ejection of chains of Pt atoms and rearrangement of the remaining surface atoms. These chains, representing the $\sim 20 \%$ difference in atomic density between the two phases, explain the anisotropy of the restructuring process. This mechanism resembles the mechanism proposed by Mase et al. [27] for NO on $\mathrm{Pt}(100)$-hex. The phase transformation is heterogeneously nucleated at linear defects, as concluded by Borg et al. [9], with an effective activation energy of $0.45 \pm 0.1 \mathrm{eV}$, although homogeneous nucleation is possible at higher activation energies. The coverage dependence of the growth rate of these heterogeneously nucleated $(1 \times 1)$ domains is nonlinear but cannot be explained-at least at higher coverages - in terms of elementary reaction kinetics as proposed by Hopkinson et al. [10] and Ali et al. [25]. This nonlinear behavior is rather explained in terms of CO-induced relaxations and a shear tension between the [011] rows of $\mathrm{Pt}$ atoms in the surface layer and the subsequent collective restructuring process.

The authors thank B. J. Thijsse for providing us with the CAMELION package. R. A. van Santen and B.G. Anderson are kindly acknowledged for valuable discussions and a careful reading of the manuscript. This work was sponsored by the NWO/SPINOZA fund; G. J. K. acknowledges the financial support of Shell Global Solutions International B.V. This work was performed under the auspices of NIOK, The Netherlands Institute for Catalysis Research.

*Electronic address: http://www.catalysis.nl/ paul ${ }^{\dagger}$ Electronic address: Gert.J.Kramer@opc.shell.com

[1] G. Ertl, Adv. Catal. 37, 213 (1990).

[2] R. Imbihl and G. Ertl, Chem. Rev. 95, 697 (1995).

[3] G. Ritz, M. Schmid, P. Varga, A. Borg, and M. Rønning, Phys. Rev. B 56, 10518 (1997).

[4] R. J. Behm, P. A. Thiel, P. R. Norton, and G. Ertl, J. Chem. Phys. 78, 7437 (1983).

[5] T. E. Jackman, K. Griffiths, J. A. Davies, and P. R. Norton, J. Chem. Phys. 79, 3529 (1983).

[6] M. Kim, W.S. Sim, and D. A. King, J. Chem. Soc. Faraday Trans. 92, 4781 (1996).

[7] P. A. Thiel, R. J. Behm, P. R. Norton, and G. Ertl, Surf. Sci. 121, L553 (1982).

[8] P. A. Thiel, R. J. Behm, P. R. Norton, and G. Ertl, J. Chem. Phys. 78, 7448 (1983).

[9] A. Borg, A.-M. Hilmen, and E. Bergene, Surf. Sci. 306, 10 (1994).

[10] A. Hopkinson, X.-C. Guo, J. M. Bradley, and D. A. King, J. Chem. Phys. 99, 8262 (1993).

[11] P. J. Feibelman, B. Hammer, J. K. Nørskov, F. Wagner, M. Scheffler, R. Stumpf, R. Watwe, and J. Dumesic, J. Phys. Chem. 105, 4018 (2001).

[12] R. J. Gelten, A. P. J. Jansen, R. A. van Santen, J. J. Lukkien, J. P. L. Segers, and P. A. J. Hilbers, J. Chem. Phys. 108, 5921 (1998).

[13] V. N. Kuzovkov, O. Kortlüke, and W. von Niessen, J. Chem. Phys. 108, 5571 (1998).

[14] V. P. Zhdanov, J. Chem. Phys. 110, 8748 (1999).

[15] F. Chávez, L. Vicente, A. Perera, and M. Moreau, J. Chem. Phys. 112, 8672 (2000).

[16] E. I. Latkin, V. I. Elokhin, and V.V. Gorodetskii, J. Mol. Catal. A: Chem. 166, 23 (2001).

[17] P. Thostrup, E. Christoffersen, H.T. Lorensen, K.W. Jacobsen, F. Besenbacher, and J. K. Nørskov, Phys. Rev. Lett. 87, 126102 (2001).

[18] M. I. Baskes, Phys. Rev. B 46, 2727 (1992).

[19] P. van Beurden and G. J. Kramer, Phys. Rev. B 63, 165106 (2001).

[20] P. van Beurden, H. G. J. Verhoeven, G. J. Kramer, and B. J. Thijsse, Phys. Rev. B 66, 235409 (2002).

[21] Y. Y. Yeo, C. E. Wartnaby, and D. A. King, Science 268, 1731 (1995).

[22] E. Ritter, R. J. Behm, G. Pötschke, and J. Wintterlin, Surf. Sci. 181, 403 (1987).

[23] J. A. Davies, T. E. Jackman, D. P. Jackson, and P. R. Norton, Surf. Sci. 109, 20 (1981).

[24] P. R. Norton, J. A. Davies, D. K. Creber, C.W. Sitter, and T. E. Jackman, Surf. Sci. 108, 205 (1981).

[25] T. Ali, B. Klötzer, A. V. Walker, and D. A. King, J. Chem. Phys. 109, 10996 (1998).

[26] V. N. Kuzovkov, O. Kortlüke, and W. von Niessen, Phys. Rev. Lett. 83, 1636 (1999).

[27] K. Mase and Y. Murata, Surf. Sci. 277, 97 (1992). 